\title{
Usulan Perbaikan Sistem Kerja Pada Proses Produksi Crumb Rubber Menggunakan Metode SHERPA Di PT. Riau Crumb Rubber Factory
}

\author{
Isum Kusumanto ${ }^{1}$, Hendra Dadang Saputra ${ }^{2}$ \\ 1,2 Jurusan Teknik Industri, Fakultas Sains dan Teknologi, UIN Sultan Syarif Kasim Riau \\ Jl. HR. Soebrantas No. 155 Simpang Baru, Panam, Pekanbaru, 28293 \\ Email:ismu_uin@yahoo.co.id, Dest Badzil@yahoo.com
}

\begin{abstract}
Abstrak
Penelitian ini dilakukan di PT. Riau Crumb Rubber Factory adalah perusahaan yang bergerak dalam pengolahan karet mentah menjadi barang setengah jadi (work in process) yang kemudian diekspor ke luar negeri. Jenis produk yang dihasilkan yaitu crumb rubber SIR-10 dan SIR-20 (Standart Indonesia Rubber). Salah satu potensi terjadinya human error yang teridentifikasi tersebut identifikasi jenis dan kejadian kesalahan kerja operator di stasiun proses kerja blower, press, metal detector dan packing. Metode yang digunakan adalah Systematic Human Error Reduction and Prediction Approach (SHERPA) Berdasarkan hasil identifikasi tersebut selanjutnya ditelusuri penyebab terjadinya kesalahan untuk ditentukan pendekatan guna mengurangi kejadian kesalahan kerja operator. Dari hasil pengolahan data potensi terjadinya human error diakibatkan karena operator menjatuhkan balok karet, operator lupa memeriksa dan operator tidak memperhatikan set-up mesin. Terdapat 11 deskripsi error dari 27 task, prediksi error yang mungkin terjadi sesuai dengan HTA dari hasil SHERPA berupa strategi perbaikan untuk meminimasi potensi terjadinya error agar dapat mengurangi resiko kesalahan. Terdapat dua macam usulan perbaikan yaitu dengan menggunakan form checklist dan SOP penggunaan mesin.
\end{abstract}

Keyword: Human Error, Crumb Rubber, SHERPA, HTA, SOP 


\section{Pendahuluan}

Dalam setiap kegiatan yang dilakukan manusia, baik kegiatan harian maupun kegiatan berproduksi pasti memerlukan metode, waktu dan tempat. Agar kegiatan mencapai tujuan yang terbaik maka diperlukan metode terbaik, tempat terbaik dan waktu terbaik. Pencapaian suatu sistem kerja akan selalu berbanding lurus dengan penggunaan serta penerapan seluruh elemen secara efektif dan efisien, salah satu elemen tersebut adalah manusia itu sendiri.

Manusia akan selalu memiliki peran penting dengan adanya kondisi tersebut, maka penyesuaian pekerjaan terhadap kemampuan manusia adalah mutlak untuk diperhatikan. Hal ini dikarenakan manusia akan selalu dibatasi oleh keterbatasan yang dimilikinya. Keterbatasan yang kemudian memungkinkan untuk timbulnya kesalahankesalahan dan dapat berdampak pada efektifitas dan performansi suatu sistem. kesalahan manusia (human error) sebagai tindakan atau prilaku manusia yang kurang sesuai atau tidak dinginkan sebagai penyebab penurunan efektivitas, keselamatan kerja, serta performansi sistem. Kesalahan manusia dapat menjadi manifestasi prilaku manusia yang dapat dikategorikan sebagai yang tidak diinginkan, tidak dapat diterima, ceroboh, lalai, lupa, berbahaya, terjadi miskomunikasi ketika berkerja, atau bentuk yang tidak tepat dari kegiatan pengambilan resiko (Iridiastadi dan Yassierli, 2014).

Penelitian ini dilakukan pada PT. Riau Crumb Rubber Factory adalah perusahaan yang bergerak dalam pengolahan karet mentah menjadi barang setengah jadi (work in process) yang kemudian diekspor ke luar negeri. Jenis produk yang dihasilkan yaitu crumb rubber SIR-10 dan SIR-20 (Standart Indonesia Rubber). Produk-produk tersebut dihasilkan melalui serangkaian proses produksi. Adapun jumlah operator dan mesin di PT. Riau Crumb Rubber Factory sebagai berikut:

Tabel Jumlah Operator dan Mesin

\begin{tabular}{|c|l|c|c|}
\hline No & \multicolumn{1}{|c|}{ Mesin } & Operator & $\begin{array}{c}\text { Mesin } \\
\text { (Unit) }\end{array}$ \\
\hline 1. & Mesin potong & 8 & 4 \\
\hline 2. & Prebreaker & 6 & 6 \\
\hline 3. & Hammermill & 12 & 6 \\
\hline 4. & Creeper & 21 & 21 \\
\hline 5. & Cutter & 1 & 1 \\
\hline 6. & Dryer & 1 & 1 \\
\hline 7. & Blower & 2 & 2 \\
\hline 8. & Metal Detector & 3 & 1 \\
\hline 9. & Pengepresan & 1 & 3 \\
\hline 10. & Pengukuran & 2 & 1 \\
\hline 11. & Packing & $\mathbf{5 1}$ & $\mathbf{4 7}$ \\
\hline
\end{tabular}

Sumber : PT. Riau Crumb Rubber Factory (2015)
Berdasarkan hasil observasi awal diketahui bahwa ada beberapa stasiun proses kerja pada produksi karet terjadinya human error, dalam proses produksi yang dilakukan pekerja dengan proses manual, operator masih melakukan kesalahan seperti, kelalaian, kelelahan, menghilangkan langkah-langkah yang harus dilakukan dan ada beberapa faktor lainnya. Kesalahan ini terjadi di stasiun kerja Blower, Press, Metal Detector dan packing dengan waktu pengamatan selama 6 hari dari Tabel 1.1 jumlah operator dan mesin.

Dari penjelasan diatas pada stasiun proses kerja blower, press, metal detector dan packing masih mengalami beberapa faktor human error. Dapat dilihat pada Gambar 1.1 stasiun kerja blower sebagai berikut:

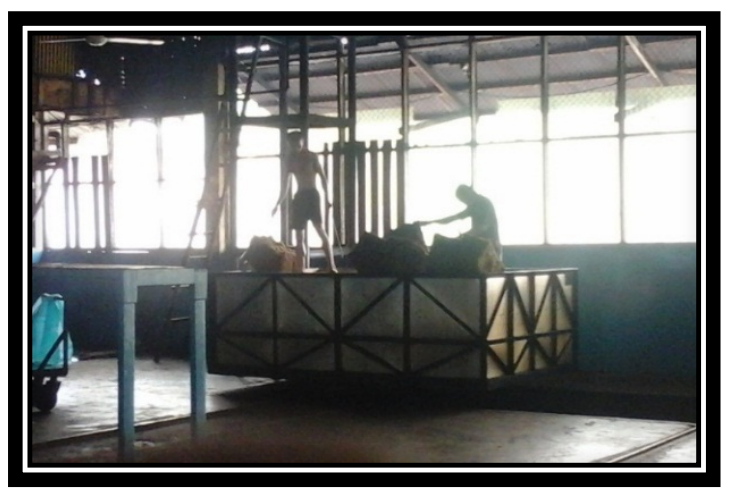

Gambar Proses Produksi Stasiun Kerja Blower

Sumber : PT. Riau Crumb Rubber Factory (2015)

Gambar 1.1 merupakan proses kerja di stasiun blower dimana proses produksi dari stasiun kerja blower ini guna untuk mendinginkan balok karet dari proses kerja dryer setelah balok didinginkan selama 2 jam maka balok karet tersebut dilakukan pada proses press. Jumlah operator di mesin blower adalah 2 orang dan lama bekerja tersebut mengindikasikan beban kerja yang harus ditanggung oleh pelaksana mesin maupun operator. Beban kerja ini berpotensi memiliki dampak pada kinerja pekerja di mesin blower ini. Hasil pengamatan mengidentifikasi beberapa kesalahan yang dilakukan operator dimana terjadi kelalaian dalam pengangkatan balok karet dan kelelahan disebabkan karena pekerja mengalami sakit pada punggung dan sakit pada lengan. Maka akibat yang ditimbulkan adalah balok karet tersebut jatuh dilantai dan mengalami kotor pada bagian balok karet tersebut. Sehingga kesalahan ini diklasifikasikan dengan tipe error ialah operating error.

Berdasarkan hasil keseluruhan pengamatan, perusahaan merasa perlu untuk mengkaji permasalahan ini dengan terlebih dahulu mengidentifikasi potensi-potensi human error pada proses kerja stasiun Blower, Prees, Metal Detector dan Packing. Dengan mendasari human error 
berdasarkan klasifikasi dan cidera yang dialami pekerja. Permasalahan ini akan diteliti melalui salah metode HEI yaitu Systematic Human Error Reduction and Prediction Approach (SHERPA). SHERPA memiliki kecocokan untuk diterapkan terhadap error yang berhubungan dengan keahlian dan kebiasaan manusia. Selain itu, metode ini memiliki konsistensi dalam mengidentifikasi error berdasarkan langkah-langkah yang sistematis dengan Hierarchy Task Analysis (HTA) sebagai input data yang akan diolah.

\section{Rumusan Masalah}

Berdasarkan pada latar belakang masalah yang telah diuraikan di atas, maka penulis dapat mengambil rumusan masalah yaitu Bagaimana mengusulkan perbaikan system kerja pada proses produksi crumb rubber guna mengurangi human error menggunakan metode SHERPA di PT. Riau Crumb Rubber Factory.

\section{Tujuan Penelitian} tujuan yaitu :

Penelitian ini dilakukan dengan beberapa

1. Mengidentifikasi jenis dan jumlah human error sehingga dilakukan re-observasi untuk menganalisis data potensi terjadinya error.

2. Menentukan usulan perbaikan dengan mengidentifikasi faktor penyebab human error untuk mengurangi terjadinya human error.

\section{Manfaat Penelitian}

Manfaat Bagi Penulis adalah :

Manfaat dari penelitian ini bagi penulis

1. Mampu menerapkan teori yang telah di dapatkan dalam perkuliahan dan sebagai pembanding teori dengan aplikasi di lapangan atau dunia kerja.

2. Menambah wawasan peneliti tentang bagaimana perkembangan dari suatu perusahaan dan pengaplikasian teknik industri untuk memecahkan masalah riil dalam dunia industri.

\section{Manfaat Bagi Perusahaan}

Adapun manfaat dari penelitan ini bagi perusahaan adalah sebagai masukan bagi pihak perusahaan mengenai kesalahan yang dilakukan manusia (human error) disetiap stasiun kerja produksi.

\section{Batasan Masalah}

Penelitian ini, penulis membuat ruang lingkup atau batasan masalah yang jelas agar pembahasan lebih terarah dan tidak terlalu luas cakupannya. Maka penulis membatasi masalah yang di teliti sebagai berikut :
1. Penelitian ini hanya terfokus pada stasiun kerja Blower, Press, Metal Detector dan Packing pada lantai produksi.

2. Penelitian ini dilakukan asumsi pekerja dalam kondisi sehat

3. Waktu pengamatan selama 6 hari

4. Identifikasi error yang dilakukan berdasarkan segi error type, konsekuensi error yang terjadi dan menggunakan metode SHERPA.

\section{Tinjauan Pustaka}

Ergonomi mayoritas diterapkan di lingkungan industri dimana lingkungan ini sangat dinamis. Perubahan selalu terjadi di industri terutama akibat adanya perubahan teknologi yang tiada hentinya. Dahulu, Frederic Charless Barlett pernah memprediksi bagaimana tantangan ergonomi pada 40 tahun yang akan datang yang ternyata cukup akurat dan sesuai dengan kondisi sekarang. Barlett memprediksikan perkembangan teknologi otomasi dan komunikasi akan menjadi tantangan yang berarti bagi ergonomi. Perkembangan teknologi tersebut mengakibatkan perubahan di aktivitas dan budaya kerja. Ini artinya ergonomi juga selalu berubah dan ergonomi di era dulu berbeda dengan ergonomi di era sekarang (Septriady, 2011).

Human error biasanya dikonotasikan dengan penyebab terjadinya suatu kejadian yang tidak diinginkan, misalnya kecelakaan. Akan tetapi, hal yang paling penting yang perlu diketahui adalah bagaimana human error yang didefenisikan sebagai tindakan yang tidak diinginkan dapat terjadi. Perlu adanya investigasi menyangkut hal tersebut. Rasmussen menyatakan bahwa investigasi mengenai penyebab terjadinya human error bergantung pada stopping rule (Sander \& McCormick dalam Iridiastadi, 2014).

SHERPA merupakan teknik yang dikembangkan oleh Embrey (1986) sebagai teknik untuk memprediksi human error yang juga menganalisis pekerjaan dan mengidentifikasi solusisolusi potensi untuk megatasi error dalam cara yang terstruktur. Teknik ini berdasarkan taksonomi human error dan pada bentuk aslinya dikhususkan pada mekanisme psikologi yang berimplikasi pada error. Error didalam SHERPA dikelompokan menjadi beberapa klasifikasi yaitu sebagai berikut:

1. Action

2. Checking

3. Retrieval

4. Information communication

5. Selection

Selain mengidentifikasi error tersebut, maka dapat dilakukan juga beberapa analisis seperti analisis terhadap kemungkinan yang dapat terjadi apabila error dilakukan oleh operator, analisis terhadap tindakan yang dianggap kritis, serta strategi 
yang dapat diberikan untuk mengatasi sebuah error tersebut (Pramono dalam kirwan dalam Iridiastadi, 2014).

\section{Metode Penelitian}

Agar penelitian yang dilakukan lebih terarah dan sistematis, maka perlu dibuat tahapantahapan dari penelitian itu sendiri. Adapun tahapan dalam penelitian ini dapat dilihat dari gambar berikut ini:

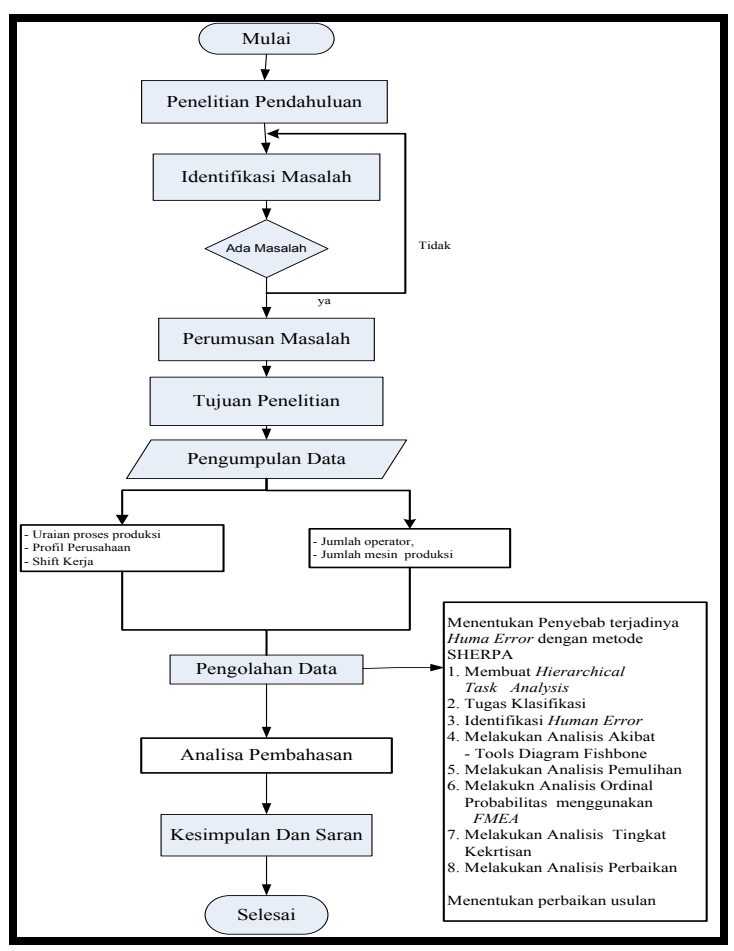

Flow Chart Tahapan Proses Penelitian

Metodologi penelitian memberikan urutan pekerjaan yang harus dilakukan peneliti dalam melakukan penelitian, teknik penelitian dengan menggunakan alat-alat pengukur yang dibutuhkan dalam melaksanakan penelitian hingga metode penelitian yang akan memandu peneliti tentang urutan penelitian yang dilakukan. Dengan demikian hasil yang diperoleh dalam melakukan penelitian memungkinkan untuk dikembangkan kembali dan menjadi dasar dari suatu proses belajar terhadap permasalahan yang ada disekitarnya.

\section{Lokasi dan Waktu Penelitian}

Penelitian dilaksanakan di PT. Riau Crumb Rubber Factory khususnya pada lini produksi yang berlokasi di jalan Kp. Sukaramai No. 63 Pekanbaru.

\section{Objek Penelitian}

Objek yang diteliti pada penelitian ini adalah operator PT. Riau Crumb Rubber Factory, guna untuk mengetahui dampak terjadinya human error (kesalahan manusia) disetiap stasiun proses kerja. Perusahaan ini memiliki banyak stasiun kerja, namun yang menjadi pokok pembahasan dalam penelitian ini adalah berapa banyak yang operator melakukan kesalahan kerja. Alasan utama yang mendasari pemilihan objek penelitian ini adalah :

1. Untuk mengurangi dampak terjadinya human error (kesalahan manusia)

\section{Penelitian Pendahuluan}

Penelitian pendahuluan diperlukan untuk meneliti lebih lanjut apa yang akan menjadi permasalahan. Penelitian pendahuluan terdiri dari studi literatur yang bertujuan untuk mendapatkan dan memperluas wawasan serta pengetahuan mengenai teori-teori yang berkaitan dengan identifikasi masalah dalam penelitian. Sedangkan pengamatan langsung dilapangan betujuan untuk mengumpulkan informasi awal tentang keadaan umum dan karakteristik perusahaan yang menjadi objek penelitian.

Hasil dari tahapan ini akan dibandingkan dengan hasil dari studi literatur untuk kemudian menentukan teknik pengukuran yang sesuai. Pada langkah ini dilakukan penelitian pendahuluan yang ada pada stasiun proses kerja yang berhubungan dengan terjadinya human error (kesalahan manusia). Penelitian pendahuluan dilakukan dengan cara observasi dan wawancara.

1. Observasi dilakukan dengan cara pengamatan atau peninjauan secara langsung ke perusahaan untuk mengetahui urutan kegiatan produksi dan kesalahan manusia yang akan terjadi

2. Wawancara dilakukan terhadap pihak perusahaan untuk mendapatkan informasi pendukung mengenai kondisi perusahaan, seperti profil perusahaan, dan faktor pendukung dalam pembuatan Tugas Akhir ini.

\section{Identifikasi Masalah}

Identifikasi masalah perlu diketahui guna mengidentifikasi masalah-masalah yang ada dalam penelitian. Identifikasi masalah bertujuan untuk mengetahui dan menggambarkan permasalahan yang ada di perusahaan, dari hasil identifikasi masalah maka akan didapat apa yang menjadi dasar permasalahan yaitu bahwa faktor terjadinya human error (kesalahan manusia) yang bisa menghambat lajunya proses produksi.

\section{Perumusan Masalah}

Penentuan rumusan masalah menjadi sangat penting karena berguna untuk merumuskan masalah dalam penelitian dan juga sebagai pedoman bagi langkah-langkah penelitian selanjutnya agar tidak menyimpang dari permasalahan yang ada, sehingga penelitian lebih terarah dan langkah-langkah 
penelitian yang akan di lakukan menjadi lebih jelas dan mudah dilaksanakan.

\section{Penetapan Tujuan}

Penetapan tujuan menunjukkan pernyataan yang berisi tentang tujuan yang ingin dicapai melalui proses penelitian. Tujuan perlu ditetapkan dalam melakukan penelitian agar lebih terarah dalam melakukan penelitian. Tujuan penelitian mengacu pada latar belakang dan berorientasi pada kepentingan perusahaan. Tujuan yang didefinisikan nantinya dihubungkan dengan permasalahan yang ada agar dapat memberikan solusi terhadap masalah tersebut.

\section{Batasan Masalah}

Masalah penelitian perlu dibatasi agar penelitian menjadi lebih terfokus dan diharapkan dapat menjawab permasalahan penelitian dengan lebih efektif dan efisien. Batasan masalah merupakan pembatasan masalah yang akan dilakukan dari penetapan tujuan agar tujuan tersebut tidak keluar dari pembahasan yang akan dilakukan selanjutnya.

\section{Hasil dan Pembahasan}

\section{Pengumpulan Data}

Metode pengumpulan data adalah suatu cara pengadaan data primer maupun sekunder untuk keperluan penelitian.

1. Data Skunder

Data skunder adalah data yang diperoleh atau dikumpulkan dan disatukan oleh studi-studi sebelumnya yang diterbitkan oleh instansi lain. Biasanya sumber tidak langsung berupa data dokumentasi dan arsip-arsip resmi. Adapun data yang diambil untuk penunjang penelitian ini di PT. Riau Crumb Rubber Factory sebagai berikut:

a. Gambaran umum perusahaan

b. Proses produksi

c. Shift kerja

d. Jumlah tenaga kerja

2. Data Primer

Data primer adalah data yang dikumpulkan oleh perorangan / suatu organisasi secara langsung dari objek yang diteliti dan untuk kepentingan studi bersangkutan yang berupa interview dan observasi. Adapun data yang diambil untuk penunjang penelitian ini di PT. Riau Crumb Rubber Factory sebagai berikut:

a. Jumlah operator

b. Jumlah mesin produksi

\section{Metode Pengolahan Data}

Setelah data diperoleh, langkah selanjutnya adalah pengolahan data dengan metode-metode yang sudah ditetapkan. Pengolahan data berisi mengenai pengolahan data-data yang diperoleh dari hasil pengumpulan data dengan melakukan pengamatan dan wawancara secara langsung tentang human error (kesalahan manusia) yang terjadi disetiap proses produksi serta dilakukan pengukuran dengan metode SHERPA sebagai berikut:

1. Membuat Hierarchical Task Analysis

Dalam tahapan ini dilakukan dengan mengetahui langkah-langkah pekerjaan (task step)

Dari HTA bagian stasiun proses kerja blower ini dapat diprediksi human error yang mungkin terjadi pada saat operator melakukan pekerjannya. Adapun Diagrammatic Hierarchical Task Analysis sebagai berikut:

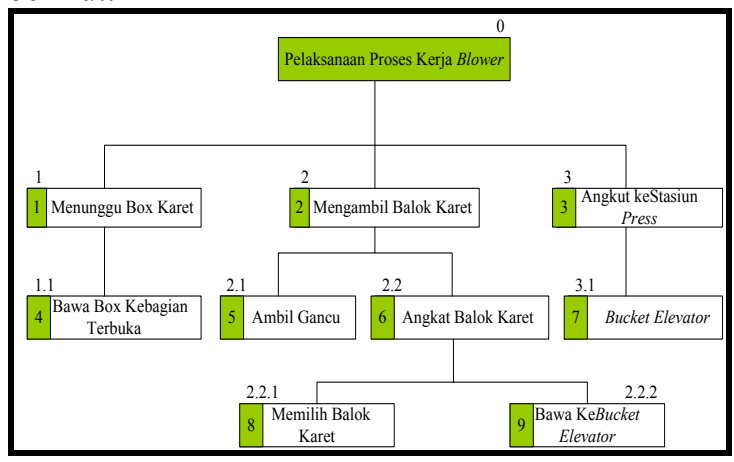

Gambar Diagrammatic HTA Pelaksanaan Proses Kerja Blower

2. Tugas klasifikasi

Dalam kategori ini yang dipilih adalah tindakan (action), pemeriksaan (checking), penerimaan informasi (retrieval), pengkomunikasian (communication), dan pemilihan (selection).

Tabel Klasifikasi Task/tugas Operator Stasiun Proses Kerja

Blower
\begin{tabular}{|c|l|l|c|}
\hline No & $\begin{array}{c}\text { No.T } \\
\text { ask }\end{array}$ & \multicolumn{1}{|c|}{ Task } & $\begin{array}{c}\text { Task } \\
\text { Classification }\end{array}$ \\
\hline 1. & 1.1 & $\begin{array}{l}\text { Bawa box kebagian } \\
\text { terbuka }\end{array}$ & Action \\
\hline 2. & 2.1 & Ambil gancu & Action \\
\hline 3. & 2.2 & Angkat balok karet & Action \\
\hline 4. & 2.2 .1 & Memilih balok karet & $\begin{array}{c}\text { Action and } \\
\text { Checking }\end{array}$ \\
\hline 5. & 2.2 .2 & Bawa kebucket elevator & Action \\
\hline 6. & 3.1 & Bucket elevator & Action \\
\hline
\end{tabular}

3. Identifikasi human error

Bagian ini merupakan penjelasan dari error yang mungkin.

Tabel Human Error Identification Bagian Stasiun Proses Kerja Blower 
4. Melakukan analisis akibat

\begin{tabular}{|c|l|c|l|}
\hline No. & $\begin{array}{c}\text { No. } \\
\text { Task }\end{array}$ & $\begin{array}{c}\text { Mode } \\
\text { Error }\end{array}$ & \multicolumn{1}{|c|}{ Deskripsi Error } \\
\hline 1. & 2.2 & A1 & $\begin{array}{l}\text { Operator menjatuhkan balok } \\
\text { karet }\end{array}$ \\
\hline 2. & 2.2 .1 & $\mathrm{C} 1$ & $\begin{array}{l}\text { Operator jarang memeriksa } \\
\text { balok karet }\end{array}$ \\
\hline 3. & 2.2 .2 & $\mathrm{~A} 2$ & $\begin{array}{l}\text { Operator kurang hati-hati dalam } \\
\text { mengangkat balok karet }\end{array}$ \\
\hline 4. & 3.1 & $\mathrm{~A} 3$ & $\begin{array}{l}\text { Operator jarang membersihkan } \\
\text { bucket elevator }\end{array}$ \\
\hline
\end{tabular}

Analisis akibat menjelaskan prediksi mengenai akibat yang mungkin terjadi apabila error tersebut dilakukan dengan alat yang digunakan adalah diagram fishbone.

Adapun penggunaan diagram sebab akibat adalah sebagai alat bantu untuk menelusuri jenis masing-masing kesalahan yang terjadi adalah sebagai berikut :

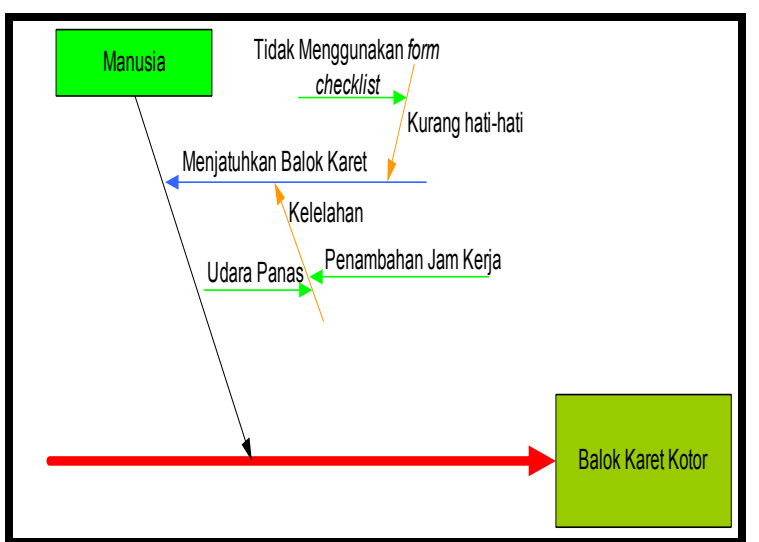

Gambar Diagram Sebab Akibat Balok Karet Kotor Bagian Stasiun Proses Kerja Blower

Sumber : Hasil Pengamatan Dan Wawancara Lapangan

5. Melakukan pemulihan

Menyatakan apakah error tersebut terdapat perbaikannya atau tidak pada langkah pekerjaan berikutnya

6. Melakukan ordinal probabilitas

Menentukan peluang terjadinya error. Nilai probabilitas berurutan dituliskan sebagai low (rendah), medium (sedang), atau high (tinggi). Alat yang digunakan untuk analisis ordinal probability adalah FMEA

Dari penyusunan FMEA pada Tabel diketahui bahwa nilai dengan Risk Point Number (RPN) terbesar terletak pada mode kegagalan press yang mengalami kesalahan dengan nilai RPN sebesar 150. Press salah satu proses yang memadatkan karet menjadi balok karet, dikarenakan kurang hati-hati atau lalai dalam melakukan proses press tersebut. Diikuti dengan proses blower dengan nilai RPN sebesar 120, dan seterusnya. RPN dalam hal ini membantu memberikan informasi bentuk kegagalan dari kesalahan yang dilakukan sehingga perlu diambil langkah prioritas penanganan.

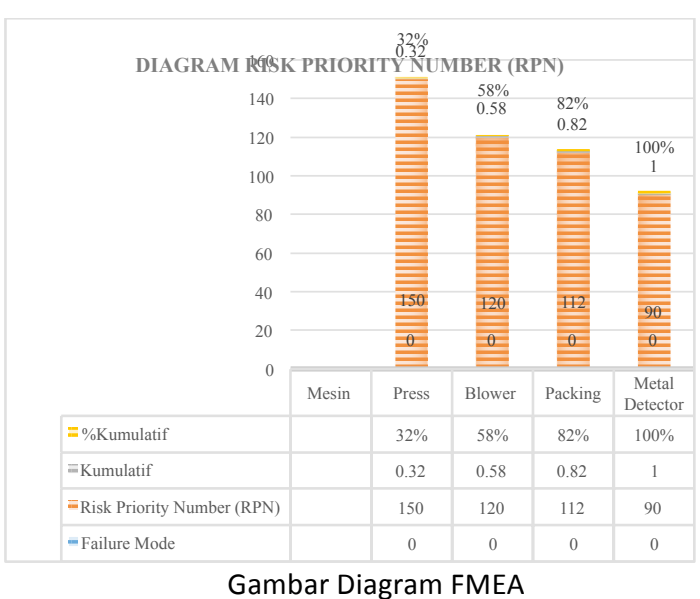

7. Melakukan analisa tingkat keritisan

Menentukan tingkat kekritisan error. Apabila konsekuensinya dianggap kritis (mengakibatkan kerugian yang tidak dapat diterima), maka dibuat suatu catatan dan kekritisan.

Table Tingkat Kekritisan
\begin{tabular}{|c|l|l|c|}
\hline No. & $\begin{array}{l}\text { No. } \\
\text { Task }\end{array}$ & \multicolumn{1}{|c|}{ konsekuensi } & Critical \\
\hline 1. & 2.2 & $\begin{array}{l}\text { Mengakibatkan balok karet } \\
\text { menjadi kotor }\end{array}$ & $!$ \\
\hline 2. & 2.2 .1 & $\begin{array}{l}\text { Masih ada balok karet yang } \\
\text { tidak sesuai standar }\end{array}$ & $!$ \\
\hline 3. & 2.2 .2 & $\begin{array}{l}\text { Mengakibatkan balok karet } \\
\text { rusak }\end{array}$ & $!$ \\
\hline 4. & 3 & $\begin{array}{l}\text { Mengakibatkan balok karet } \\
\text { menjadi kotor }\end{array}$ & $!$ \\
\hline 5. & 2.1 & $\begin{array}{l}\text { Tidak sesuai standar yang } \\
\text { ditetapkan }\end{array}$ & $!$ \\
\hline 6. & 2.3 & $\begin{array}{l}\text { Masih terdapat balok karet } \\
\text { yang rusak }\end{array}$ & $!$ \\
\hline 7. & 4 & $\begin{array}{l}\text { Balok karet menjadi kotor } \\
\text { Balok karet menjadi kotor }\end{array}$ \\
\hline 8. & 1 & $\begin{array}{l}\text { Masih ada sisa balok karet yang } \\
\text { kotor }\end{array}$ & $!$ \\
\hline 9. & 3 & $\begin{array}{l}\text { Mengakibatkan bungkusan } \\
\text { packing rusak }\end{array}$ & - \\
\hline 10. & 3.2 & - \\
\hline 11. & 3.1 .1 & Bingkisan packing rusak & \\
\hline
\end{tabular}


8. Melakukan analisa pemulihan

Bagian terakhir ini dijelaskan tentang usulan perbaikan agar error tersebut dapat diminimasi.

Table Analisis Pemulihan

\begin{tabular}{|c|l|l|}
\hline No. & No. Task & \multicolumn{1}{c|}{ Recovery } \\
\hline 1. & 2.2 & Melakukan kembali perbaikan \\
\hline 2. & 2.2 .1 & Melakukan kembali perbaikan \\
\hline 3. & 2.2 .2 & Melakukan kembali perbaikan \\
\hline 4. & 3 & Melakukan kembali perbaikan \\
\hline 5. & 2.1 & Melakukan kembali perbaikan \\
\hline 6. & 2.3 & Melakukan kembali perbaikan \\
\hline 7. & 4 & Melakukan kembali perbaikan \\
\hline 8. & 1 & Melakukan kembali perbaikan \\
\hline 9. & 3 & Melakukan kembali perbaikan \\
\hline 10. & 3.2 & Tidak terdapat perbaikan \\
\hline 11. & 3.1 .1 & Tidak terdapat perbaikan \\
\hline & &
\end{tabular}

9. Membuat tabel SHERPA

Dari beberapa langkah dalam menggunakan SHERPA maka bisa mengetahui terjadinya human error (kesalahan manusia). Serta dilakukan penyusunan SHERPA output dari Hierarchical Task Analysis yang berupa diagram dekomposisi yang menjabarkan langkah-langkah pekerjaan dalam memproduksi sebuah produk pada mesin sampai mendapatkan level terendah dari pekerjaan tersebut.

Tabel Failure Mode And Effect Analysis

\begin{tabular}{|c|c|c|c|c|c|c|c|c|c|c|c|}
\hline \multicolumn{8}{|c|}{ POTENTIAL FAILURE MODE AND EFFECT ANALYSIS } & \multicolumn{4}{|c|}{ (PROSES FMEA) } \\
\hline \multicolumn{2}{|c|}{ Mesin } & : Lantai Prod & & \multicolumn{2}{|c|}{$\begin{array}{l}\text { Proses yang } \\
\text { ditanggung }\end{array}$} & \multicolumn{2}{|c|}{$\begin{array}{l}\text { : Proses di Lantai } \\
\text { Produksi }\end{array}$} & $\begin{array}{l}\text { Nomor } \\
\text { FMEA }\end{array}$ & $: 1$ & & \\
\hline \multicolumn{2}{|c|}{$\begin{array}{l}\text { Model } \\
\text { Tahun }\end{array}$} & \multicolumn{2}{|l|}{$:-$} & \multicolumn{2}{|l|}{$\begin{array}{l}\text { Tanggal } \\
\text { Penerapan }\end{array}$} & \multicolumn{2}{|l|}{ :- } & Dibuat Oleh & \multicolumn{3}{|c|}{$\begin{array}{l}\text { : Hendra Dadang } \\
\text { Saputra }\end{array}$} \\
\hline \multicolumn{2}{|c|}{$\begin{array}{l}\text { Tim } \\
\text { Penyusun } \\
\text { Inti }\end{array}$} & \multicolumn{2}{|c|}{$\begin{array}{l}\text { : Hendra Dadang Saputra } \\
\text { dan } \\
\text { Kepala Produksi }\end{array}$} & & & & & $\begin{array}{l}\text { Tanggal } \\
\text { Pembuatan }\end{array}$ & \multicolumn{3}{|c|}{ : 02 Februari 2016} \\
\hline $\begin{array}{l}\mathrm{N} \\
\mathrm{o}\end{array}$ & $\begin{array}{c}\text { Kompo } \\
\text { nen / } \\
\text { Proses }\end{array}$ & $\begin{array}{c}\text { Fungsi } \\
\text { Komponen / } \\
\text { Proses }\end{array}$ & $\begin{array}{c}\text { Mode } \\
\text { Kegagalan } \\
\text { Potensial }\end{array}$ & $\begin{array}{c}\text { Akibat } \\
\text { Kegagalan } \\
\text { Kompone } \\
\text { n / Proses }\end{array}$ & $\mathrm{S}$ & $\begin{array}{l}\text { Penyebab } \\
\text { Kegagalan }\end{array}$ & $\mathrm{O}$ & $\begin{array}{l}\text { Kontrol yang } \\
\text { Dilakukan }\end{array}$ & $\mathrm{D}$ & RPN & $\begin{array}{l}\mathrm{Ra} \\
\mathrm{nk}\end{array}$ \\
\hline 1. & Blower & $\begin{array}{l}\text { Mendingink } \\
\text { an balok } \\
\text { karet }\end{array}$ & $\begin{array}{l}\text { Operator } \\
\text { menjatuhk } \\
\text { an balok } \\
\text { karet }\end{array}$ & $\begin{array}{l}\text { Balok } \\
\text { karet } \\
\text { menjadi } \\
\text { kotor/rusa } \\
\text { k }\end{array}$ & 4 & $\begin{array}{l}\text { Kelalaian } \\
\text { yang } \\
\text { dilakukan } \\
\text { operator }\end{array}$ & 6 & $\begin{array}{l}\text { Lebih hati-hati } \\
\text { dan focus }\end{array}$ & 5 & 120 & 2 \\
\hline 2. & Press & $\begin{array}{l}\text { Pengepresan } \\
\text { balok karet }\end{array}$ & $\begin{array}{l}\text { Operator } \\
\text { tidak } \\
\text { memperha } \\
\text { tikan } \\
\text { tekanan } \\
\text { press }\end{array}$ & $\begin{array}{l}\text { Tidak } \\
\text { sesuai } \\
\text { standar } \\
\text { yang } \\
\text { ditetapkan }\end{array}$ & 5 & $\begin{array}{l}\text { Operator } \\
\text { tidak } \\
\text { memeriksa } \\
\text { tekenan press }\end{array}$ & 5 & $\begin{array}{l}\text { Perlunya } \\
\text { pengawasan }\end{array}$ & 6 & 150 & 1 \\
\hline 3. & $\begin{array}{c}\text { Metal } \\
\text { Detecto } \\
r\end{array}$ & $\begin{array}{l}\text { Mengirim } \\
\text { balok karet } \\
\text { dari press } \\
\text { menuju } \\
\text { packing }\end{array}$ & $\begin{array}{l}\text { Operator } \\
\text { lupa } \\
\text { memriksa } \\
\text { balok } \\
\text { karet }\end{array}$ & $\begin{array}{l}\text { Balok } \\
\text { karet } \\
\text { menjadi } \\
\text { kotor/rusa } \\
\text { k }\end{array}$ & 3 & $\begin{array}{l}\text { Operator lupa } \\
\text { memeriksa } \\
\text { balok karet }\end{array}$ & 5 & $\begin{array}{l}\text { Perlunya } \\
\text { pengawasan }\end{array}$ & 6 & 90 & 4 \\
\hline 4. & Packing & $\begin{array}{l}\text { Pembungku } \\
\text { san balok } \\
\text { karet }\end{array}$ & $\begin{array}{l}\text { Operator } \\
\text { tidak } \\
\text { memperha } \\
\text { tikan } \\
\text { panas } \\
\text { solder } \\
\text { yang } \\
\text { digunakan }\end{array}$ & $\begin{array}{l}\text { Bungkusa } \\
\text { n packing } \\
\text { rusak }\end{array}$ & 4 & $\begin{array}{l}\text { Operator } \\
\text { tidak hati- } \\
\text { hati }\end{array}$ & 7 & $\begin{array}{l}\text { Operator } \\
\text { berhati-hati }\end{array}$ & 4 & 112 & 3 \\
\hline
\end{tabular}


Tabel SHERPA Pada Bagian Stasiun Proses Kerja Blower, Press, Metal detector dan Packing

\begin{tabular}{|c|c|c|c|c|c|c|c|c|}
\hline No. & $\begin{array}{l}\text { No. } \\
\text { Task }\end{array}$ & $\begin{array}{l}\text { Mode } \\
\text { Error }\end{array}$ & Deskripsi Error & Akibat & Pemulihan & $\mathbf{P}$ & $\mathbf{C}$ & $\begin{array}{c}\text { Strategi } \\
\text { Perbaikan }\end{array}$ \\
\hline 1. & 0.2 .2 & A1 & $\begin{array}{l}\text { Operator } \\
\text { menjatuhkan balok } \\
\text { karet }\end{array}$ & $\begin{array}{l}\text { Mengakibatkan } \\
\text { balok karet } \\
\text { menjadi kotor } \\
\end{array}$ & $\begin{array}{l}\text { Melakukan } \\
\text { kembali perbaikan }\end{array}$ & $\mathrm{H}$ & - & $\begin{array}{l}\text { Menggunakan alat } \\
\text { bantu }\end{array}$ \\
\hline 2. & 0.2 .2 .1 & $\mathrm{C} 1$ & $\begin{array}{l}\text { Operator jarang } \\
\text { memeriksa balok } \\
\text { karet }\end{array}$ & $\begin{array}{l}\text { Masih ada balok } \\
\text { karet yang tidak } \\
\text { sesuai standar }\end{array}$ & $\begin{array}{l}\text { Melakukan } \\
\text { kembali perbaikan }\end{array}$ & $\mathrm{H}$ & - & $\begin{array}{l}\text { Melakukan } \\
\text { pemeriksaaan } \\
\text { secara rutin }\end{array}$ \\
\hline 3. & 0.2 .2 .2 & A2 & $\begin{array}{l}\text { Operator kurang } \\
\text { hati-hati dalam } \\
\text { mengangkat balok } \\
\text { karet }\end{array}$ & $\begin{array}{l}\text { Mengakibatkan } \\
\text { balok karet rusak }\end{array}$ & $\begin{array}{l}\text { Melakukan } \\
\text { kembali perbaikan }\end{array}$ & $\mathrm{H}$ & - & $\begin{array}{l}\text { Menggunakan alat } \\
\text { bantu }\end{array}$ \\
\hline 4. & 0.3 & A3 & $\begin{array}{l}\text { Operator jarang } \\
\text { membersihkan } \\
\text { bucket elevator }\end{array}$ & $\begin{array}{l}\text { Mengakibatkan } \\
\text { balok karet } \\
\text { menjadi kotor } \\
\end{array}$ & $\begin{array}{l}\text { Melakukan } \\
\text { kembali perbaikan }\end{array}$ & $\mathrm{H}$ & - & $\begin{array}{l}\text { Menggunakan alat } \\
\text { bantu }\end{array}$ \\
\hline 5. & 0.2 .1 & A4 & $\begin{array}{l}\text { Operator tidak } \\
\text { memperhatikan } \\
\text { tekanan press yang } \\
\text { digunakan }\end{array}$ & $\begin{array}{l}\text { Tidak sesuai } \\
\text { standar yang } \\
\text { ditetapkan }\end{array}$ & $\begin{array}{l}\text { Melakukan } \\
\text { kembali perbaikan }\end{array}$ & $\mathrm{H}$ & - & $\begin{array}{l}\text { Secara rutin } \\
\text { memeriksa } \\
\text { settingan press }\end{array}$ \\
\hline 6. & 0.2 .3 & $\mathrm{C} 2$ & $\begin{array}{l}\text { Operator kurang } \\
\text { memperhatikan } \\
\text { pemeriksaan balok } \\
\text { karet }\end{array}$ & $\begin{array}{l}\text { Masih terdapat } \\
\text { balok karet yang } \\
\text { rusak }\end{array}$ & $\begin{array}{l}\text { Melakukan } \\
\text { kembali perbaikan }\end{array}$ & $\mathrm{M}$ & - & $\begin{array}{l}\text { Menggunakan } \\
\text { buku dengan } \\
\text { metode checklist }\end{array}$ \\
\hline 7. & 0.4 & A2 & $\begin{array}{l}\text { Operator kurang } \\
\text { berhati-hati }\end{array}$ & $\begin{array}{l}\text { Balok karet } \\
\text { menjadi kotor }\end{array}$ & $\begin{array}{l}\text { Melakukan } \\
\text { kembali perbaikan }\end{array}$ & $\mathrm{M}$ & - & $\begin{array}{l}\text { Menggunakan alat } \\
\text { bantu }\end{array}$ \\
\hline 8. & 0.1 & A2 & $\begin{array}{l}\text { Operator kurang } \\
\text { hati-hati }\end{array}$ & $\begin{array}{l}\text { Balok karet } \\
\text { menjadi kotor }\end{array}$ & $\begin{array}{l}\text { Melakukan } \\
\text { kembali perbaikan }\end{array}$ & $\mathrm{L}$ & - & $\begin{array}{l}\text { Menggunakan alat } \\
\text { bantu }\end{array}$ \\
\hline 9. & 0.3 & $\mathrm{C} 3$ & $\begin{array}{l}\text { Operator lupa } \\
\text { memeriksa balok } \\
\text { karet }\end{array}$ & $\begin{array}{l}\text { Masih ada sisa } \\
\text { balok karet yang } \\
\text { kotor }\end{array}$ & $\begin{array}{l}\text { Melakukan } \\
\text { kembali perbaikan }\end{array}$ & $\mathrm{M}$ & - & $\begin{array}{l}\text { Melakukan } \\
\text { pemeriksaaan } \\
\text { secara rutin }\end{array}$ \\
\hline 10. & 0.3 .2 & A4 & $\begin{array}{l}\text { Operator tidak } \\
\text { memperhatikan } \\
\text { panas solder yang } \\
\text { digunakan }\end{array}$ & $\begin{array}{l}\text { Mengakibatkan } \\
\text { bungkusan } \\
\text { packing rusak }\end{array}$ & $\begin{array}{l}\text { Tidak terdapat } \\
\text { perbaikan }\end{array}$ & $\mathrm{L}$ & $!$ & $\begin{array}{l}\text { Memperhatikan } \\
\text { settingan panas } \\
\text { solder }\end{array}$ \\
\hline 11. & 0.3 .1 .1 & A2 & $\begin{array}{l}\text { Operator tidak } \\
\text { berhati-hati }\end{array}$ & $\begin{array}{l}\text { Bingkisan } \\
\text { packing rusak }\end{array}$ & $\begin{array}{l}\text { Tidak terdapat } \\
\text { perbaikan }\end{array}$ & $\mathrm{L}$ & $!$ & Hati-hati \\
\hline
\end{tabular}




\section{Hasil dan Pembahasan}

Analisis data merupakan analisa yang dilakukan dengan menganalisa hasil pengolahan data guna untuk melakukan analisa pemecahan masalah yang berguna untuk menentukan usulan perbaikan. Adapun analisis data dari hasil pengolahan sebagai berikut:

1. Membuat Hierarchical Task Analysis

2. Tugas klasifikasi

3. Identifikasi human error

4. Melakukan analisis akibat

5. Melakukan pemulihan

6. Melakukan ordinal probabilitas

7. Melakukan analisa tingkat keritisan

8. Melakukan analisa perbaikan

9. Tabel SHERPA

10. Tindakan usulan mengatasi penyebab kesalahan

11. Tindakan usulan pemeriksaan menggunakan form checklist

12. Standard Operational Procedure (SOP) Penggunaan Mesin

\section{Kesimpulan}

Berdasarkan pengolahan data dan pembahasan analisa pada penelitian ini, maka dapat diambil kesimpulan sebagai berikut:

1. Berdasarkan hasil dari pengolahan data terdapat 11 deskripsi error dari 27 task yang terbagi kedalam 3 (tiga) klasifikasi

2. Terdapat 2 (dua) macam usulan perbaikan yaitu from checklist dan SOP penggunaan mesin. From checklist diusulkan sebagai alat pengecekan bagi tiap operator yang memiliki bagian inspeksi. SOP diusulkan sebagai mengingat operator dalam penggunaan mesin sehingga dapat meminimasi terjadinya error guna dapat terhindar dari resiko.

\section{Saran}

Saran yang diberikan setelah penelitian ini dilakukan adalah sebagai berikut:

1. Perusahaan perlu melakukan pengawasan pada setiap sistem kerja dan pekerjaanya yang terjadi beberapa kesalahan operator (human error) dan meningkatkan lingkungan kerja yang baik untuk mengurangi stress pekerja, diantaranya pengawasan distasiun proses kerja blower, press, metal detector dan packing.
2. Melakukan inspeksi setiap proses kerja guna untuk meminimalisir kesalahan yang dilakukan operator.

3. Penelitian lebih lanjut pada setiap mesin dilantai produksi dalam kondisi yang bagus guna untuk mengetahui kesalahan yang akan muncul

4. Hasil penelitian tidak menutup kemungkinan untuk melakukan kajian error lebih lanjut. Dan diharapkan ada yang mengembangkannya yang lebih baik lagi dimasa yang akan datang.

\section{Daftar Pustaka}

Ansori Nachnul, Mustajib M. Imron. Sistem Perawatan Terpadu, (Integraded Maintenance System), Graha Ilmu, Yogyakarta, 2013.

Bukhori. Kajian Human Error dan Violation Pada Aktivitas Rig Up Menara Rig 350-Horse Power, Lokasi Well Service, PT. Pertamina EP Region Jawa Field Jatibarang. Depok: Tesis, Program Magister Keselamatan dan Kesehatan Kerja, 2012.

Fajar, Yanti, Arie. Usulan Perbaikan Sistem Kerja Mesin Bending di PT. X Menggunakan Metode Systematic Human Error Reduction and Prediction Approach (SHERPA). Bandung: Jurusan Teknik Industri, Institut Teknologi Nasional, 2015.

Hardianto Iridiastadi, Yassierli. Ergonomi Suatu Pengantar. Bandung: PT. Remaja Rosdakarya, 2014.

Masruroh Ir. Nisa. Perencanaan Kegiatan Perawatan Pada Unit Produksi Butiran (padat) Dengan Basic RCM (Reability Centered Maintenance) Di PT. Petrokimia Kayaku Gresik, 2008.

Mehdi, Jebrail. Application of SHERPA to Identify and Prevent Human Factor in Control Units of Petrochemical Industry. International Journal of Occupational Safety and Ergonomics (JOSE), Vol. 19, No.2, 203-209, 2013.

Pangaribuan, Dina Meliana. Analisa Postur Kerja dengan Metode RULA pada Pegawai Bagian Pelayanan perpustakaan USU Medan. Medan: Tugas Akhir, Jurusan Teknik Industri, Universitas Sumatera Utara, 2009.

Septriady, Dela Agung. Analisis Desain Ergonomi Pintu Masuk Kendaraan Tempur Lapis Baja Armoured Personel Carrier (APC) dalam Virtual Environment. Depok: Tugas Akhir, 
Jurusan Teknik Industri, Universitas Indonesia, 2011.

Sutarna, I Nyoman. Aplikasi Ergonomi pada Proses Pemotongan Pelat Eser Meningkatkan Kinerja mahasiswa di bengkel Teknologi Mekanik Politeknik Negeri Bali. Denpasar: Tesis, Program Pascasarjana, Universitas Udayana, 2011.

Sutrio dan Firdaus, Oktri Mohammad. Analisa Pengukuran RULA dan REBA Petugas pada Pengangkatan barang di Gudang dengan Menggunakan Software ErgoIntelligence (Studi Kasus : Petugas Pembawa Barang di Toko Dewi Bandung). Jurnal Prosiding Seminar nasional RITEKTRA. Bandung: Jurusan Teknik Industri, Universitas Widyatama, 2011.

Yuniarto, Dewi, Aini. Perbaikan Pada Fishbone Diagram Sebagai Root Cause analysis Toll. Yogyakarta: Tugas Akhir, Jurusan Teknik Industri, Universitas Gajah Mada, 2012. 